\section{US database link helps open up Japan to the West}

Tokyo

JAPAN'S Ministry of Education, Culture and Science (MESC) is poised to counter charges that the information flow between the West and Japan is mostly in one direction, by giving US researchers on-line access to its scientific databases. Computers at Tokyo's National Center for Science Information System (NCSIS) and the Washington headquarters of the US National Science Foundation (NSF) have just been linked through international telecommunication lines and will reach out to US researchers through NSF networks from April.

The new link, which will be extended to the United Kingdom and then Europe next year, complements efforts by the Science and Technology Agency to internationalize the massive databases it runs at the Japan Information Center of Science and Technology (JICST). But there is still some way to go to provide electronic satisfaction to US negotiators' demands for "comparable access" including access to basic technological research in private companies - voiced during negotiation earlier this year of the US-Japan Science and Technology Agreement (see Nature 337, 396; 2 February 1989).
NCSIS's Professor Shoichiro Asano hopes that the first step, of providing access to MESC's academic databases, may make it possible for Japan to tackle the more difficult second and third steps of widening access to government research institutes and to research in private industry. Much of the latter research, he points out, is "invisible" even to Japanese eyes. The US link is being financed entirely by MESC, with technical back-up and administrative help from NSF. Asano is hopeful that this 'present' will demonstrate Japan's commitment to open communication.

For foreign researchers, the most valuable feature of the new link may be access to abstracts of academic conferences held in Japan. Abstracts are now often available in electronic form a few weeks after a conference takes place and long before a full scientific paper is published. Asano says that academic societies in the fields of electronics, computer and information sciences are making special efforts to ease foreign access by providing abstracts in English; researchers in the chemical and medical sciences are not far behind. Presentation and format will improve, he says, as evaluation comes in from foreign researchers.

\title{
Europe's fast reactor plan inches forward
}

\section{Bonn}

France, West Germany, Britain and several other European countries have taken a further step in their plan to develop a fast reactor in collaboration with each other.

Representatives of the governments and their participating research institutes and industries last week signed the formal agreement meant to carry them forward to the next phase of the project - that of the detailed design of a $1,500 \mathrm{MW}$ fast reactor, which should be completed by 1993 . If built, the reactor would cost $£ 2,000$ million.

The new design will essentially be based on that of the French Superphénix 1, but will have either three or six coolant circuits and will be smaller in size. Superphénix 1 itself was restarted only last month, 18 months after it was closed on account of a leak from a liquid sodium circuit.

The three-year design programme will cost $£ 190$ million over three years, with France, West Germany and the United Kingdom each paying nearly a third. Belgium, Denmark, the Netherlands and Italy will make smaller contributions. John Collier, chairman of the UK Atomic Energy Authority, says that it would be possible for the reactor to be built and operating by 2000 , provided that construc- tion funds and an agreed site for the reactor could be found.

France, considered to be the leader in fast reactor development, is the most likely provider of a site, especially because of the political opposition expected in Britain and West Germany. By 2005, France will in any case need new sources of electricity generation to replace its earlier generations of nuclear reactors. But, in the past few years, the economic advantages of fast reactors have been challenged by the emergence of the spectral-shift pressurizedwater reactor.

The continued support of the United Kingdom for the project is uncertain following the government's decision that its own fast-reactor development programme should be cut from $£ 110$ million a year to $£ 10$ million a year. The electricity supply industry, which is soon to be privatized, seems to be an unlikely alternative source of funds.

The future of West German participation is also uncertain. The demonstration fast reactor at Kalkar in North RhineWestphalia does not yet have an operating licence after 16 years of construction, 18 planning permits and DM7,000 million of investment.
The link also provides electronic mail, and access to the on-line academic library network and MESC's database of grants for scientific research. The ordinary user will, however, be restricted to the fraction of the database written in English, as special equipment (which has been installed at NSF headquarters) is needed to display Japanese characters. But information in English should help target material worth translating.

The language problem is not easily overcome. In late 1987, JICST began international on-line service by linking its own databases (which emphasize space and nuclear power) with the Chemical Abstracts Service in the United States and the Energy, Physics and Mathematics data-base (FIZ-Karlsruhe) in West Germany, but so far the flow of information has been mainly to Japan. The part of JICST data base of particular interest to foreigners concerns Japanese research; most of that is in Japanese and therefore inaccessible. JICST looks for a solution in machine translation, on which it is working hard. But a further problem may still remain: even when special projects, like that at George Mason University in Virginia, have given access to Japanese data, few US researchers have shown interest.

Alun Anderson

\section{Chinese satellites look to the future London}

CHina's hopes of becoming a major launcher of space vehicles and satellites may have dimmed in recent years but have not been entirely extinguished. The difficulties of the US shuttle programme and the Ariane launcher had raised the prospect that China's 'Long-March-3' rocket might be used to launch satellites from overseas. But planners and experts at a meeting last month acknowledged that foreign competition and the restrictions imposed by the Coordinating Committee for East-West Trade Policy (COCOM) were a barrier to the commercial exploitation of Chinese launch facilities.

What the meeting decided is that, in the circumstances, China would have to offer a complete service, including sophisticated satellite technology, and not just launch facilities. Experts present took the view that the Chinese technology for retrieving satellites has a competitive advantage, especially if it is possible to develop a recoverable satellite for microgravity experiments, for which an important market is expected.

Meanwhile, China plans to concentrate on the use and development of communications and remote-sensing satellites. There are plans for a space station and a shuttle, but these are not expected to become realities this century. 